\title{
SOME PERSONAL ERRORS IN POINT SAMPLING ${ }^{1}$
}

\author{
By D. D. MUNRO²
}

\section{INTRODUCTION}

Point sampling, also referred to as Bitterlich, prism, wedge prism, relascope sampling or plotless cruising has been accepted by most North American foresters as a valid forest sampling method. Discovered by Bitterlich (1948) and introduced to North America by Grosenbaugh (1952), it rapidly became the subject of widespread discussion and research. Comprehensive discussions of theory and field applications were presented by Grosenbaugh (1958), Beers and Miller (1964) and Dilworth and Bell (1963). Thomson and Deitchman (1959) listed 129 references on point sampling for the period 1947 to 1959 .

Numerous tests comparing point sampling with conventional plot sampling have been documented. Recently, exhaustive tests have been carried out with the aid of electronic computers on the efficiency, precision and accuracy of point sampling (Palley and O'Regan, 1961; O'Regan and Palley, 1965; Kulow, 1966). These tests point out clearly the superiority of point sampling-as much as two times as efficient as plot sampling in terms of total volume and basal area.

Because point samples are based on a relatively small number of trees per plot, a small error in tree count usually results in a large percentage error in the determination of volume or basal area per acre. The purpose of this paper is to investigate the magnitude and variation of tree counts resulting from personal errors and to establish some guidelines for check cruising. In other words, this paper attempts to answer the questions "what variation in tree count can one expect to find among repeated measurements taken by different persons at the same sampling point and how does this variation affect the sampling error of an operational prism cruise?" No attempt will be made to analyse errors other than those which occur in the field use of the prism and which affect the actual number of trees at a particular sample point.

\section{Sources of Error IN Tree Count}

Although careful field work can minimize personal errors it cannot entirely eliminate them. Most authors suggest the need for proper crew instruction, careful supervision and a continuous program of check cruising to ensure high quality field work and reliable data. The most common causes of error in tree count (all in the general category of personal error) are the following:

1. Failure to maintain the prism directly over the centre of the plot: the beginner often makes the mistake of standing at the plot centre and moving the prism around himself. This results in an overestimate of tree count.

2. Failure to align the prism correctly: on level ground the prism must be held with its central plane perpendicular to the line of sight and its base perpendicular to the stem of the tree being measured. Incorrect alignment can result in either an under or overestimation of tree count.

\footnotetext{
'Presented to the Annual Meeting of the Canadian Institute of Forestry, Banff, Alta., October, 1966.

${ }^{2}$ Graduate student and part-time lecturer, Faculty of Forestry, University of British Columbia, Vancouver, B.C.
} 
3. Failure to correct for slope: on sloping ground the central plane of the prism must be perpendicular to the line of sight and the base of the prism must be rotated through an angle equal to the angle of slope of the line of sight. Failure to correct for slope will result in an underestimation of tree count.

4. Failure to check "borderline" trees: care is needed to determine whether trees which are apparently borderline are really inside or outside the plot. The exact status of all such trees should be determined by measurement and critical distance calculations (Beers and Miller, 1964). "Guessing" at borderline trees results in many tree count errors.

5. Failure to make a full 360 degree sweep: a definite starting and ending point must be selected in order that omissions and double counts are eliminated.

\section{Method of Data Collection}

A total of sixteen permanent points were selected in a 70-year old stand of Western hemlock, Douglas fir and Western red cedar on the U.B.C. Research Forest at Haney, B.C. (University of British Columbia, 1959). Site index ranged from 120 feet to 140 feet at one hundred years; volume per acre averaged 6000 cubic feet gross. Tree diameter ranged from 10 to 30 inches at breast height. Topography varied from flat to steep; ground vegetation and underbrush were not dense enough to seriously affect vision.

Prism plots using basal area factor 30 were established at each of these points by two graduate foresters, each with considerable experience in point sampling. All doubtful trees were carefully measured for diameter and distance from the centre point of the plot. Critical distances were calculated to determine if such trees were inside or outside the plot. Particular care was taken at each point to ensure accuracy. This set of measurements formed the control for the experiment.

These same plots were then measured independently by sixteen 2-man crews of students from the third year forestry class at the University of British Columbia. These students previously had approximately nine hours of classroom lectures and problems on prism sampling theory and three hours of field instruction and practice. A few of the students had spent one summer point sampling for private forest companies. The students were informed of the purpose of the experiment but estimates were independent. Crews were instructed to measure and check all apparent borderline trees. Diameters of all trees were measured at breast height to the nearest one tenth inch. Trees were tallied in order of occurrence, clockwise from the direction of strip, so that tree by tree comparisons could be made quickly among crews and within plots. All measurements were made during favourable weather conditions.

\section{ANalyses and Results}

The data were analysed in three separate ways. Firstly the variation in crew measurements at each point was assessed. With sixteen independent sets of measurements at each sampling point it was possible to calculate a measure of variation for tree count at each point and to pool these to obtain a weighted average variation per point. Table 1 summarizes some statistics for each of the sixteen points. 
DECEMBER, 1966

TABLE 1

Plot Statistics Among 16 Crews

\begin{tabular}{rrrrrrr}
\hline $\begin{array}{c}\text { Plot } \\
\text { No. }\end{array}$ & actual & \multicolumn{6}{c}{$\begin{array}{c}\text { Number of trees tallied } \\
\text { max. }\end{array}$} & min. & avg. & stan. dev. & coef. var. $\%$ \\
\hline A & 6 & 8 & 5 & 6.12 & 0.932 & 15.23 \\
B & 9 & 10 & 6 & 8.25 & 1.000 & 12.12 \\
C & 5 & 6 & 4 & 5.31 & 0.603 & 11.36 \\
D & 8 & 9 & 6 & 7.31 & 0.876 & 11.98 \\
E & 10 & 12 & 8 & 9.69 & 1.302 & 13.44 \\
F & 6 & 9 & 6 & 6.37 & 0.807 & 12.67 \\
G & 11 & 11 & 8 & 10.25 & 1.153 & 11.25 \\
H & 7 & 8 & 6 & 7.44 & 0.630 & 8.47 \\
I & 4 & 4 & 4 & 4.00 & 0.000 & 0.00 \\
J & 8 & 8 & 6 & 7.56 & 0.751 & 9.93 \\
K & 6 & 7 & 5 & 6.00 & 0.634 & 10.57 \\
L & 9 & 10 & 8 & 8.94 & 0.443 & 4.95 \\
M & 6 & 7 & 6 & 6.19 & 0.403 & 6.51 \\
N & 7 & 8 & 6 & 6.87 & 0.718 & 10.45 \\
O & 6 & 9 & 4 & 5.87 & 1.025 & 17.46 \\
P & 10 & 10 & 7 & 9.69 & 0.794 & 8.19 \\
\hline Average & 7.375 & - & - & 7.219 & 0.805 & 11.15 \\
\hline
\end{tabular}

Control tree counts per point ranged from a low of four trees to a high of eleven trees. The standard deviation and coefficient of variation are tabulated for each plot. These statistics would all be "zero" if every crew had obtained an identical tree count at each point. It is important to realize that these measures of dispersion are not valid for the stand ... . they are measures of the variation of tree count among sixteen crews at each point and as such are valid estimates of the variation in personal error associated with tree counts. The pooled standard deviation is 0.805 trees per point. This is remarkably close to the standard deviation of 1 tree per point estimated by Ker, Smith and Walters (1957) in similar stands. The pooled coefficient of variation, 11.5 per cent, is an estimate of the reliability with which the trees in a plot can be counted. For example, in this stand the tree count at any point might be in error by 11.15 per cent at the p. 68 significance level.

The average tree count for all plots and crews compares favourably with the control. There is a slight negative bias which is not statistically significant.

Secondly, the data were sorted by crews and variability statistics were calculated for the plot data. This analysis provided sixteen independent estimates of the coefficient of variation of the stand. It was then possible to obtain an estimate of the variability of the coefficient of variation. Table 2 presents this information by crew number and averages for all plots. The total tree count by crews varied from a low of 108 trees to a high of 125 trees. The control count was 118 trees. It is interesting that the estimates of variability ranged from 22.26 per cent to 31.86 per cent, but that the average for all crews is almost identical with the control value. 
Thirdly, each plot measurement was treated independently. The accuracy of tree count was calculated by using the total number of plot measurements which in this case is 256 ( 16 plots times 16 crews). Table 3 shows the variations in tree count encountered both by number of plots and by percentage figures. The maximum tree count error tabulated per point was \pm three trees and this occurred on only 6 of the 256 plot measurements.

TABLE 2

\section{Crew Statistics Among 16 Plots}

\begin{tabular}{ccccc}
\hline $\begin{array}{c}\text { Crew } \\
\text { No. }\end{array}$ & $\begin{array}{c}\text { Total } \\
\text { all plots }\end{array}$ & $\begin{array}{c}\text { Number of trees tallied } \\
\text { Average } \\
\text { per plot }\end{array}$ & $\begin{array}{c}\text { Stan. der. } \\
\text { per plot }\end{array}$ & $\begin{array}{c}\text { Coef. var. } \\
\%\end{array}$ \\
\hline control & 118 & 7.375 & 1.990 & 26.98 \\
1 & 122 & 7.625 & 1.893 & 24.83 \\
2 & 116 & 7.250 & 2.295 & 31.65 \\
3 & 113 & 7.062 & 1.572 & 22.26 \\
4 & 122 & 7.625 & 2.242 & 29.40 \\
5 & 125 & 7.812 & 1.908 & 24.42 \\
6 & 113 & 7.062 & 1.808 & 25.60 \\
7 & 115 & 7.187 & 1.908 & 26.55 \\
8 & 108 & 6.750 & 1.771 & 26.24 \\
9 & 112 & 7.000 & 1.675 & 23.93 \\
10 & 116 & 7.250 & 2.190 & 30.21 \\
11 & 115 & 7.187 & 1.873 & 26.06 \\
12 & 116 & 7.250 & 1.880 & 25.93 \\
13 & 113 & 7.062 & 2.250 & 31.86 \\
14 & 115 & 7.187 & 2.108 & 29.33 \\
15 & 112 & 7.000 & 1.678 & 23.97 \\
16 & 115 & 7.187 & 1.941 & 27.01 \\
\hline Average & 115.5 & 7.219 & 1.949 & 27.00 \\
(excluding control) & & & \\
\hline
\end{tabular}

TABLE 3

Tree Count Accuracy

\begin{tabular}{cccc}
\hline $\begin{array}{c}\text { Variation from } \\
\text { control } \\
\text { (no. of trees) }\end{array}$ & No. of plots & \% of total & $\begin{array}{c}\text { \% of total } \\
\text { (cumalative) }\end{array}$ \\
\hline nil & 149 & 58.21 & 58.21 \\
\pm 1 & 87 & 33.98 & 92.19 \\
\pm 2 & 14 & 5.47 & 97.66 \\
\pm 3 & 6 & 2.34 & 100.00 \\
Total & 256 & 100.00 & - \\
\hline
\end{tabular}




\section{DISCUSSION}

It is important to realize that in point sampling the tree count per point bears a strong relationship to the actual volume per acre at that point. Tree diameter is relatively unimportant in volume determination because the trees are selected by the prism in proportion to their basal area. Individual tree height is the most important parameter in volume determination from point samples. If the relationship between tree diameter and height is uniform throughout a series of point samples, then volume per point and basal area per point will be nearly perfectly correlated.

Since basal area per acre is a function of tree count per point, it follows logically that tree count per point will be highly correlated with volume per acre. Any variability in tree count among a series of points is to a great extent an indication of the variability of volume per acre between the points. In most practical applications, the coefficient of variation of tree count can be assumed to be equivalent to the coefficient of variation of volume per acre. Therefore conclusions reached regarding variability in tree count can be assumed to apply with reasonable consistency to volume.

The pooled coefficient of variation of personal tree count error of 11.15 per cent (table 1) is the most important single statistic in the analysis. It indicates that the personal error in the determination of volume per acre from a single prism point can be as much as \pm 11.15 per cent at the p.68 significance level or \pm 22.30 per cent at the p.95 significance level. Personal errors of this magnitude should be sufficient to encourage any conscientious forester to initiate a check cruising program immediately if he has not already done so! It is gratifying, however, to discover that the laws of probability rapidly diminish the size of this error when a series of plots is established. In theory, this error is inversely proportional to the square root of the number of plots established. Thus for example, if 25 plots were established in a type, the personal error or total volume determination would reduce to $11.15 / 5$ or \pm 2.23 per cent at the p.68 significance level (similarly \pm 4.46 per cent at the p.95 significance level).

The independent estimates of the coefficients of variation of the stand (table 2) provide some interesting statistics for consideration. An analysis showed that a single estimate of the coefficient of variation based on sixteen plots may be in error by 5.56 absolute units at the p.95 significance level. In practical terms in the stand examined here it means that the indicated number of plots required to reach a given level of sampling error could conceivably range from a low of 0.63 to a high of 1.45 times the true number of plots required. For example, to attain a sampling error of \pm 10 per cent at the p.95 significance level the true number of plots required would be: $n=\frac{t^{2} c^{2}}{a^{2}}$ where " $n$ " is the number of plots required; " $t$ " is a statistical constant ( 2 in this example); "c" is the coefficient of variation; and "a" is the sampling error desired.

$$
\mathrm{n}=\frac{(2)^{2}(27)^{2}}{10^{2}}=29.16 \text { or } 30 \text { plots. }
$$


If the coefficient of variation were estimated within the p.95 significance limits the indicated number of plots required could range from $0.63 \times 30$ or 19 plots to $1.45 \times 30$ or 44 plots. The necessity for an accurate determination of the coefficient of variation is obvious.

The total average tree count per crew of 115.5 trees (table 2) is slightly less than, though not statistically different from, the true count of 118 trees. This indicates an overall negative bias of 2.8 per cent. A careful examination of the data revealed no apparent reasons for this bias. It seems that each crew simply missed two or three trees on the total number of plots. No consistent relationship could be found between personal error and the number of trees per point, slope of plot, and size, species or position of trees within the plot.

Guidelines for check cruising (table 4) were derived from table 3. The variation from control should be considered as average for competent but relatively inexperienced field personnel. Persons experienced in point sampling should do better.

TABLE 4

Guidelines For CHeCK CRUising

\begin{tabular}{cccccc}
\hline $\begin{array}{c}\text { Variation from } \\
\text { check } \\
\text { (no. of trees) }\end{array}$ & $\mathbf{5}$ & $\begin{array}{c}\mathbf{1 0} \\
\text { probable no. of plots with personal "errors" of }\end{array}$ & $\begin{array}{c}\text { No.3 trees } \\
\mathbf{1 5}\end{array}$ & $\mathbf{2 5}$ \\
\hline nil & 3 & 6 & 9 & 12 & 15 \\
\pm 1 & 2 & 4 & 5 & 7 & 8 \\
\pm 2 & 0 & 0 & 1 & 1 & 1 \\
\pm 3 & 0 & 0 & 0 & 0 & 1 \\
\hline
\end{tabular}

\section{CONCLUSIONS}

A total of sixteen sample points was examined independently by sixteen 2-man crews using 30 basal area factor prisms. An analysis of the data indicates that:

1. The pooled coefficient of variation of personal tree count errors is 11.15 per cent.

2. Individual crew estimates of the coefficient of variation of the stand varied by \pm 5.56 absolute units at the p.95 significance level.

3. A small but statistically insignificant negative bias in tree count was noted.

4. No consistent relationship was observed between personal error and number of trees per plot, slope of plot, and size, species or position of trees within the plot.

5. About 58 per cent of all plots were measured without error and 92 per cent of all plots had errors of \pm 1 tree or less. 


\section{BIBLIOGRAPHY}

BEERS, T. W. and C. I. MILLER. 1964. Point sampling: research results and theory and applications. Research Bulletin No. 786. Purdue University, Agricultural and Experiment Station, Lafayette, Indiana. $54 \mathrm{p}$.

BITTERLICH, W. 1948. Die Winkelzahlprobe. Allg. Forst-u. Holzw. Ztg. 59: 4-5. Original not seen. Abstracted in For. Abstracts. 10: $2314,1949$.

DILWORTH, J. R. and J. F. BELL. 1963. Variable plot cruising. O.S.U. Bookstores Inc. Corvallis, Oregon. 107 p.

GROSENBAUGH, L. R. 1952. Plotless timber estimates - new, fast, easy. Journal of Forestry. 50: $1 ; 32-37$

GROSENBAUGH, L. R. 1958. Point sampling and line sampling: probability, theory, geometric implications, synthesis. Occ. Paper 160. Southern Forest Experiment Station. U.S.D.A. $34 \mathrm{p}$.

KENDALL, R. H. and L. SAYN-WITTGENSTEIN. 1959. An evaluation of the relascope. Technical Note No. 77. Canada Dept. of Forestry, Ottawa, Ont. 26 p.

KER, J. W., SMITH, J. H. G. and J. WALTERS, 1957. Observations on the accuracy and utility of plotless cruising. British Columbia Lumberman, November, 1957.

KULOW, D. L. 1966. Comparisons of forest sampling designs. Journal of Forestry 64: 7; 469-474.

O'REGAN, W. G. and MARSHALL N. PALLEY. 1965. A computer technique for the study of forest sampling methods. Forest Science: 11: 1; 100-114.

PALLEY, MARSHALL N. and W. G. O'REGAN. 1961. A computer technique for the study of forest sampling methods. Forest Science: 7: 3; 282-293.

SMITH, J. H. G. and D. D. MUNRO. 1965. Point sampling and merchantable volume factors for the commercial trees of British Columbia. Faculty of Forestry, The University of British Columbia, Vancouver 8, B.C. 39 pp.

THOMSON, GEORGE W. and GLENN H. DEITSCHMAN, 1959. Bibliography of world literature on the Bitterlich method of plotless cruising. Agricultural and Home Economics Experiment Station. Ames, Iorra. $10 \mathrm{pp}$.

UNIVERSITY OF BRITISH COLUMBIA. 1959. The first decade of management and research - U.B.C. Forest 1949-1958. Faculty of Forestry, University of British Columbia, Vancouver 8, B.C. 82 pp.

UNIVERSITY OF BRITISH COLUMBIA. 1965. Seminar on point sampling in British Columbia: past, present and future (proceedings). Department of Extension, The University of British Columbia, Vancouver 8, B.C. 53 pp. 